\title{
Systemic steroids in severe forms of COPD exacerbations: a question of balance?
}

\author{
Thomas Similowski ${ }^{1,2,3}$ and Samy Suissa ${ }^{4,5}$
}

Affiliations: 'Sorbonne Universités, UPMC Univ Paris 06, UMR_S 1158 “Neurophysiologie Respiratoire Expérimentale et Clinique", Paris, ${ }^{2}$ INSERM, UMR_S 1158 "Neurophysiologie Respiratoire Expérimentale et Clinique", Paris, and ${ }^{3}$ AP-HP, Groupe Hospitalier Pitié-Salpêtrière Charles Foix, Service de Pneumologie et Réanimation Médicale (Département "R3S"), Paris, France. ${ }^{4 C}$ entre for Clinical Epidemiology, Lady Davis Institute, Jewish General Hospital, Montreal, QC, and ${ }^{5}$ Dept of Epidemiology, Biostatistics and Occupational Health, McGill University, Montreal, QC, Canada.

Correspondence: T. Similowski, Dept of Respiratory and Critical Care Medicine, Pitié-Salpêtrière Hospital, 47-83 Bd de l'Hôpital, 75651 Paris Cedex 13, France. E-mail: thomas.similowskiapsl.aphp.fr

@ERSpublications

Systemic steroids in mechanically ventilated COPD: the absence of obvious benefit should make prescription the exception http://ow.ly/spRFx

Chronic obstructive pulmonary disease (COPD) is a lung disorder with systemic inflammatory-related consequences, for which there is no cure. Beside tobacco cessation (of which the beneficial effects are many), the only available therapeutic interventions in COPD target exercise-related dyspnoea and exacerbations. There is extensive solid evidence to support the use of bronchodilators and pulmonary rehabilitation to address these clinically relevant issues [1]. The corpus of data supporting the beneficial effects of pulmonary rehabilitation is vast and has been built through the years by several convergent studies from independent investigators [2]. It is widely acknowledged that locomotor muscles are dysfunctional in COPD [3], and also widely acknowledged that rehabilitation in COPD improves exercise tolerance, decreases the rate of exacerbations, ameliorates quality of life and might prolong survival in certain contexts (e.g. after an exacerbation of the disease) $[2,4,5]$. Exercise training (or re-training) is a major driver of the success of pulmonary rehabilitation in COPD. Thus, the current state of the evidence suggests that patients with COPD who want to tackle their disease should quit smoking, inhale bronchodilating substances, be they associated or not with corticosteroids, and seriously think about rebuilding the strength and endurance of their meagre quadriceps. To do so, exercise is needed, but so is an adequate balance between muscle anabolism and muscle catabolism.

It is at this point that this editorial connects with the article that it accompanies, although through a contorted route. In this issue of the European Respiratory Journal, ABROUG et al. [6] report data that are first of their kind on the effects of systemic steroids in patients admitted to an intensive care unit (ICU) and requiring ventilatory support for a severe, life-threatening exacerbation of COPD. In an open-label, randomised trial of 217 patients, ABROUG et al. [6] observed no difference between patients receiving standard care or standard care plus $1 \mathrm{mg} \cdot \mathrm{kg}^{-1}$ of prednisone, in terms of ICU mortality, the rate of noninvasive ventilation failure, the duration of mechanical ventilation or the ICU length of stay. How are these observations relevant to our quadriceps story? Because systemic steroids are classically known to tip the balance between muscle anabolism and muscle catabolism toward the side of catabolism [7], resulting in a loss of muscle mass, possibly involving myostatin upregulation [8]: proximal muscle weakness is among typical features of hypercorticism $[9,10]$. Yet, a great many critically ill patients exhibit increased catabolism as a consequence of their acute state, with both locomotor muscle and respiratory muscle the clinical victims of this aggression [11,12]: preserving muscle mass is a major clinical concern for all intensivists. Systemic steroids can be beneficial in some of these clinical situations if they effectively interrupt an

Received: Jan 012014 | Accepted: Jan 062014

Conflict of interest: Disclosures can be found alongside the online version of this article at www.erj.ersjournals.com

Copyright @ERS 2014 
inflammatory process. If this is not the case, however, they do have the capacity to bring more harm than remedy. In patients with severe COPD experiencing an exacerbation, an early study of the effects of nutritional support [13] showed a negative nitrogen balance in all the patients where it was calculated. There was a statistically significant inverse correlation between nitrogen balance and the cumulative dose of methylprednisolone received, and between handgrip strength and nitrogen balance [13]. Corticosteroids are listed among the factors of striated muscle dysfunction during acute respiratory failure of COPD [14] and negative relationships between muscle strength and the cumulative dose of steroids received for COPD exacerbations have also been reported [15]. In COPD patients who have been intubated and are mechanically ventilated, the occurrence and severity of ICU-acquired myopathy (documented by electrophysiological studies and biopsies) has been related to the dose of systemic steroids received [16], with consequences as severe as prolonged mechanical ventilation and prolonged hospital stay. Of note, systemic steroids in ICU patients (COPD notwithstanding) can increase the risk of ICU-acquired polyneuromyopathy, directly or by contributing to hyperglycaemia, an independent risk factor of this entity [17] is an obvious cause of quadriceps atrophy and weakness. The "steroid-COPD-ICU-muscle" picture is thus rather gloomy: it is then only a small step to conclude that having received systemic steroids during a severe exacerbation will not help a COPD patients who survive the ICU stay (and fortunately this is the majority, with in-hospital mortality of acute respiratory failure of COPD lower than that of many other causes of respiratory failure $[18,19])$ start and achieve a successful rehabilitation. This would be a lesser problem if the said steroids had major other benefits. The study by ABroug et al. [6] suggests that this is not the case in the most severe category of COPD exacerbations, those that require ventilatory assistance.

This study has one major merit, which is to provide novel and long awaited clinical data on an important issue. It is, however, not devoid of drawbacks and limitations, and points to issues of consideration by future studies. First, with respect to sample size calculations, we should question whether the goal is attainable. Indeed, this trial was designed to have $80 \%$ power to detect a $12 \%$ decrease in ICU mortality, i.e. from $22 \%$ to $10 \%$, corresponding to a $55 \%$ relative reduction. This is enormous. Not many interventions can claim to reduce mortality rates to such a level. In fact the study was underpowered, as it was stopped early, and cannot preclude a $40 \%$ relative reduction in ICU mortality, which is also quite massive and rather unrealistic. A second issue is whether the study should be so restrictive in its patient population. Indeed, patients treated for a COPD exacerbation with systemic steroids in the 30 days prior to screening were excluded. These 160 excluded patients represent a significant number relative to the 217 included in the trial. Is it reasonable to exclude such patients when they represent an important portion of those seen routinely in the ICU? Future trials may wish to include patients who had a treated exacerbation, if the trial is to have wide value for clinical practice. In addition, it may be worthwhile to reconsider the 74 patients excluded because of evidence for pneumonia when $25 \%$ of the included patients had an unidentified cause for their AECOPD. The third issue relates to the statistical analysis in view of the small study size, which led to some imbalances in the groups. Indeed, the patients randomised to prednisone were older than the control patients by 2 years and had COPD for 2 years longer. A 2 -year age difference is not negligible in terms of mortality among 70-year old COPD patients, while a longer COPD duration reflects a history of more exacerbations, which is also related to higher mortality risk during an exacerbation [20]. A statistical analysis that adjusts for these and other factors may provide a somewhat more accurate estimate of the effect, albeit power will remain an issue. Finally, the open-label nature of the randomised trial can be problematic. While the authors correctly point out the absence of bias from reporting hard end-points such as death, open-label trials can induce imbalances in other treatments prescribed specifically because of the "openness" of the intervention, and could affect the outcome. While this did not turn out to be the case in this trial, antibiotics could very well have been given differentially to patients who did not receive the trial prednisone, and could affect mortality. It is unclear how the results of such a trial would then be interpreted.

In spite of these limitations, the study by ABroug et al. [6] must be taken as what it is, namely a stern, wellfounded warning against the routine (and at times "instinctive") prescription of systemic steroids in COPD patients needing acute ventilatory support. Indeed, beyond the nitrogen and the anabolism-catabolism balances discussed above, and that this study does not directly address, what the results of ABROUG et al. [6] show is that the risk-benefit balance of systemic steroids in this indication is negative, not only because there is no clear benefit to weight but also because there is some weight on the risk plate of the scale with severe hyperglycaemia occurring more often in the "prednisone" group. This side-effect has already been reported as clouding the benefits of systemic steroids in less severe COPD exacerbations [21] and is of particular concern in the general management of the critically ill [22]. It is true that further studies are needed, including trials with a more robust design and perhaps even large-scale, well-designed observational studies, before definitive conclusions are drawn. Meanwhile, treatment guidelines could be reviewed and clinicians should exert caution and discernment. They should prescribe systemic steroids in ICU-managed COPD patients only if they have a particular reason to do so and not let themselves be driven by the 
momentum of habit. Hopefully, sticking to primum non nocere in this instance will make it easier for those patients to benefit, after their ICU stay, from what there is actual evidence for, namely efficient exercise training in the context of pulmonary rehabilitation.

\section{References}

1 Vestbo J, Hurd SS, Agusti AG, et al. Global strategy for the diagnosis, management, and prevention of chronic obstructive pulmonary disease: GOLD executive summary. Am J Respir Crit Care Med 2013; 187: 347-365.

2 Spruit MA, Singh SJ, Garvey C, et al. An official American Thoracic Society/European Respiratory Society statement: key concepts and advances in pulmonary rehabilitation. Am J Respir Crit Care Med 2013; 188: e13-64.

3 Gea J, Agusti A, Roca J. Pathophysiology of muscle dysfunction in COPD. J Appl Physiol (1985) 2013; 114: $1222-1234$.

Burtin C, Decramer M, Gosselink R, et al. Rehabilitation and acute exacerbations. Eur Respir J 2011; 38: 702-712. Puhan MA, Gimeno-Santos E, Scharplatz M, et al. Pulmonary rehabilitation following exacerbations of chronic obstructive pulmonary disease. Cochrane Database Syst Rev 2011; 10: CD005305.

6 Abroug F, Ouanes-Besbes L, Fkih-Hassen M, et al. Prednisone in COPD exacerbation requiring ventilatory support: an open-label randomised evaluation. Eur Respir J 2014; 43: 717-724.

7 Tomas FM, Munro HN, Young VR. Effect of glucocorticoid administration on the rate of muscle protein breakdown in vivo in rats, as measured by urinary excretion of $\mathrm{N}$ tau-methylhistidine. Biochem J 1979; 178: 139-146.

8 Ma K, Mallidis C, Bhasin S, et al. Glucocorticoid-induced skeletal muscle atrophy is associated with upregulation of myostatin gene expression. Am J Physiol Endocrinol Metab 2003; 285: E363-E371.

9 Cushing H. The basophil adenomas of the pituitary body and their clinical manifestations (pituitary basophilism). Bull Johns Hopkins Hosp 1932; 50: 137-195.

10 Muller R, Kugelberg E. Myopathy in Cushing's syndrome. J Neurol Neurosurg Psychiatry 1959; 22: 314-319.

11 Demoule A, Jung B, Prodanovic H, et al. Diaphragm dysfunction on admission to the intensive care unit. Prevalence, risk factors, and prognostic impact - a prospective study. Am J Respir Crit Care Med 2013; 188: 213-219.

12 Khan J, Harrison TB, Rich MM, et al. Early development of critical illness myopathy and neuropathy in patients with severe sepsis. Neurology 2006; 67: 1421-1425.

13 Saudny-Unterberger H, Martin JG, Gray-Donald K. Impact of nutritional support on functional status during an acute exacerbation of chronic obstructive pulmonary disease. Am J Respir Crit Care Med 1997; 156: 794-799.

14 Gayan-Ramirez G, Decramer M. Mechanisms of striated muscle dysfunction during acute exacerbations of COPD. J Appl Physiol 2013; 114: 1291-1299.

15 Decramer M, Lacquet LM, Fagard R, et al. Corticosteroids contribute to muscle weakness in chronic airflow obstruction. Am J Respir Crit Care Med 1994; 150: 11-16.

16 Amaya-Villar R, Garnacho-Montero J, Garcia-Garmendia JL, et al. Steroid-induced myopathy in patients intubated due to exacerbation of chronic obstructive pulmonary disease. Intensive Care Med 2005; 31: 157-161.

17 Latronico N, Bolton CF. Critical illness polyneuropathy and myopathy: a major cause of muscle weakness and paralysis. Lancet Neurol 2011; 10: 931-941.

18 Funk GC, Bauer P, Burghuber OC, et al. Prevalence and prognosis of COPD in critically ill patients between 1998 and 2008. Eur Respir J 2013; 41: 792-799.

19 Gunen H, Hacievliyagil SS, Kosar F, et al. Factors affecting survival of hospitalised patients with COPD. Eur Respir J 2005; 26: 234-241.

20 Suissa S, Dell'Aniello S, Ernst P. Long-term natural history of chronic obstructive pulmonary disease: severe exacerbations and mortality. Thorax 2012; 67: 957-963.

21 Niewoehner DE, Erbland ML, Deupree RH, et al. Effect of systemic glucocorticoids on exacerbations of chronic obstructive pulmonary disease. Department of Veterans Affairs Cooperative Study Group. N Engl J Med 1999; 340: 1941-1947.

22 Jacobi J, Bircher N, Krinsley J, et al. Guidelines for the use of an insulin infusion for the management of hyperglycemia in critically ill patients. Crit Care Med 2012; 40: 3251-3276. 